\title{
Cerebral Venous Thrombosis: A Rare Complication of Spinal Anesthesia
}

\author{
Raphael M. Kabore ${ }^{*}$, Habib A. K. Ouiminga ${ }^{2}$, Labodi Lompo1, H. Desire Sankara3, \\ Anselme Dabilgou ${ }^{4}$, Alassane Drave5, Svetlana Barro Cherban', Christian Napon ${ }^{7}$, \\ Athanase Millogo ${ }^{8}$, Jean Kabore ${ }^{4}$
}

${ }^{1}$ Department of Neurology, CHU Tengandogo, Ouagadougou, Burkina Faso

${ }^{2}$ Department of Neurosurgery, CHU Tengandogo, Ouagadougou, Burkina Faso

${ }^{3}$ Deparement of Imagery, CHU Tengandogo, Ouagadougou, Burkina Faso

${ }^{4}$ Department of Neurology, CHU Yalgado OUEDRAOGO, Ouagadougou, Burkina Faso

${ }^{5}$ Department of Neurology, CHU Ouahigouya, Ouahigouya, Burkina Faso

${ }^{6}$ Department of Anesthesia-Reanimation, CHU Tengandogo, Ouagadougou, Burkina Faso

${ }^{7}$ Department of Neurology, CHU Bogodogo, Ouagadougou, Burkina Faso

${ }^{8}$ Department of Neurology, CHU-Souro SANOU, Bobo-Dioulasso, Burkina Faso

Email: ^raphkabore@yahoo.fr

How to cite this paper: Kabore, R.M., Ouiminga, H.A.K., Lompo, L., Sankara, H.D., Dabilgou, A., Drave, A., Cherban, S.B., Napon, C., Millogo, A. and Kabore, J. (2021) Cerebral Venous Thrombosis: A Rare Complication of Spinal Anesthesia. World Journal of Neuroscience, 11, 1-7. https://doi.org/10.4236/wjns.2021.111001

Received: January 26, 2020

Accepted: January 29, 2021

Published: February 1, 2021

Copyright $\odot 2021$ by author(s) and Scientific Research Publishing Inc. This work is licensed under the Creative Commons Attribution International License (CC BY 4.0).

http://creativecommons.org/licenses/by/4.0/ (c) (i) Open Access

\begin{abstract}
Introduction: Cerebral venous thrombosis (CVT) is a rare complication of spinal anesthesia. The diagnosis is difficult when it occurs by isolated headache, following post spinal puncture headache (PSPH). We report a case of cerebral venous thrombosis complicating PSPH, following a spinal anesthesia. Observation: A 23-year-old man was admitted to the emergency room for PSPH appeared 6 hours after a spinal aesthesia for removal of osteosynthesis equipment from the right tibial plateau. The headache was fronto-occipital, relieved by lying down. Six days later, headache became permanent, not relieved by morphine, associated with vomiting. The neurological examination was normal. Brain magnetic resonance Magnetic venography showed superior sagittal sinus and right transverse sinus thrombosis. After administration of low molecular weight heparin at curative dose, and warfarin under INR control, the evolution was marked by a rapid regression of headaches on the same day. After a 1-year setback, the patient was asymptomatic. Conclusion: CVT is a rare complication of spinal anesthesia and potentially severe if diagnosed lately. Urgent brain imaging must be performed for any atypical headache or the onset of neurological disorders so as not to misunderstand cerebral vein thrombosis. Controlling the spine anesthesia would reduce the inadvertent perforation of the dura-mother that would lead to CVT complicating post spinal puncture headaches.
\end{abstract}




\section{Keywords}

Spinal Anesthesia, Post Spinal Puncture Headache, Cerebral Venous

Thrombosis

\section{Introduction}

Post spinal puncture headaches (PSPH) are a known complication of spinal anesthesia [1] [2]. They occur in $10 \%$ to $30 \%$ of patients, and are usually mild in evolution and exceptionally associated with complications [1] [2] [3]. Cases of cerebral venous thrombosis, cerebral hematomas have been reported after spinal anesthesia for caesarean section, abdominal surgery [1] [4]. Cerebral venous thrombosis is a rare complication of spinal anesthesia [3]. When it occurs, the consequences could be serious with a mortality rate of $5 \%$ to $10 \%$ [4] [5]. The most common symptoms are almost constant headache, focal neurological disorders (seizures, disturbances in consciousness) and papilledema [5]. Its diagnosis is difficult when it manifests itself in isolated headache, following spinal anesthesia. We report a case of cerebral venous thrombosis (CVT) complicating $\mathrm{PSPH}$, following spinal anesthesia.

\section{Clinical Observation}

A 23-year-old man was admitted to the emergency room for post spinal puncture headache (PSPH) appeared 6 hours after a spinal aesthesia for removal of osteosynthesis equipment from the right tibial plateau. A stabilization of a fracture of the right tibial plateau had been performed 1 year earlier. He did not have a previous personal or family history of stroke or clotting disorder. The headache was fronto-occipital, very intense, initially relieved by lying down. The neurological examination noted a Glasgow score at 15 without sensorymotor deficit. Deep tendon reflexes were normal, and there was no meningeal irritation. The diagnosis of post spinal puncture headache (PSPH) was mentioned. Treatment included intravenous administration of analgesic, Paracetamol 4 grams per day, and Tramadol 300 milligrams per day. After 6 days of hospitalization, the headache became persistent and permanent, not relieved by morphine and associated with vomiting. The level of D-dimers was increased to 1.57 micrograms per $\mathrm{ml}$ (normal value lower than 0.5 micrograms per $\mathrm{ml}$ ). Brain magnetic resonance venography (MRV) showed a hypointense signal on T1 weighted sequence (A) and sagittal venogram (B) in the posterior sagittal sinus. Another hypointense signal was found the in right transverse sinus on axial venogram (Figure $1(\mathrm{C})$ ), and there were no hemorrhagic injuries. The diagnosis of cerebral venous thrombosis (CVT) was confirmed. Biological tests for infection, hemostasis abnormality, and the level of protein $\mathrm{C}$ and $\mathrm{S}$ were normal. Anticoagulation was initiated with low molecular heparin (LMWH), enoxaparin 1 $\mathrm{mg} / \mathrm{kg}$ subcutaneously every 12 hours. After two days, LMWH therapy was 


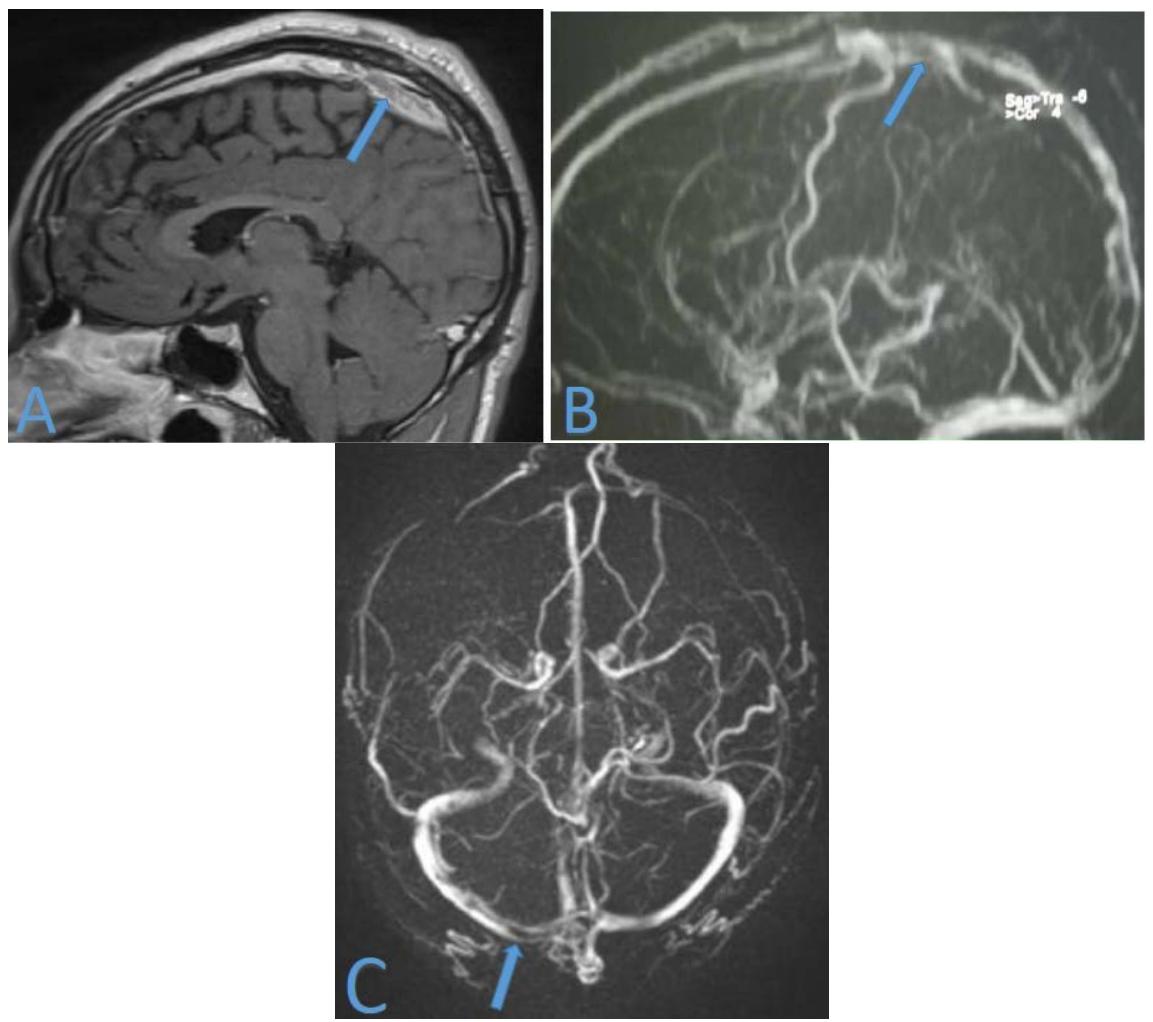

Figure 1. Brain magnetic resonance venography (MRV) showing a hypointense signal on T1 weighted sequence (A) and sagittal venogram (B) in the posterior sagittal sinus. Axial venogram showing a hypointense signal in the right transverse sinus $(\mathrm{C})$

continued by Antivitamin k with warfarin (Coumadin) $5 \mathrm{mg}$ per day. The evolution was marked by a rapid regression of headaches on the following day, and the next day the patient was asymptomatic. He was discharged of hospital after 10-days. Warfarin (Coumadin) was continued $5 \mathrm{mg}$ per day for 6 months with INR control (between 2 and 3). After a 1-year follow-up the patient was asymptomatic.

\section{Discussion}

Cerebral venous thrombosis (CVT) is an exceptional complication after spinal anesthesia [1] [2] [4]. It particularly affects young adults between 20 and 50 years old [6]. Our patient is in this age group and was male. In published journals, there is rather a female predominance [2]. During pregnancy, increased estrogen levels influence the tone of the brain vessels, and thereby increase vascular distension in response to hypotension of the cerebrospinal fluid (CSF) [2]. Pushing efforts during vaginal delivery can increase the size of the dural puncture and the loss of CSF, leading to the development of post spinal puncture headache (PSPH). The postulated cause of the headache is reduced CSF pressure due to the loss of CSF in the epidural space through the puncture site. The decrease in CSF pressure would result in a loss of the damping effect normally provided by the intracranial fluid. The resulting traction placed on intracranial 
pain-sensitive structures elicits pain. Another theory that with a sudden drop in CSF pressure, vasodilation of intracranial vessels occurs to maintain a constant intracranial volume, resulting in a pathophysiology similar to vascular headache [2]. The pathogenesis of CVT induced by spinal puncture can be explained by the Monro-Kellie doctrine. This theory suggests that the skull is a rigid structure in which intracranial components, brain tissues, blood and CSF are in a state of pressure balance. In pathological conditions, the decrease or increase of one of these elements will cause a compensatory change in the volume of the others, so that the intracranial content remains constant. In the specific case of spinal puncture, when CSF hypotension occurs, the volume and pressure of the CSF are significantly reduced [2] [7]. Increased volemia in the venous system will compensate for decreased CSF volume and lead to venous dilation. Consequently, blood flow is slowed down, and decreased absorption of CSF through the venous network resulting in increased blood viscosity. These abnormalities would lead to cerebral venous thrombosis [1] [5] [6] and can explain our observation. Our patient had spinal anesthesia for removal of osteosynthesis equipment from the right tibial plateau. He complained headache 6 hours later, and post spinal headache was evoqued. He received classical analgesic, Paracetamol 4 grams per day, and Tramadol 300 milligrams per day, and finaly morphin without improvement. The level of D-dimers was increased to 1.57 micrograms per $\mathrm{ml}$, and brain magnetic resonance venography (MRV) confirmed cerebral venous thrombosis. But questions remain about the role of slowing the blood flow and blood hyperviscosity in the genesis of thrombosis. Hemostasis abnormalities consisting of deficiencies in protein $\mathrm{C}, \mathrm{S}$, antithrombin III, factor VIII or a lupus anticoagulant have been found in patients who have developed CVT following spinal anesthesia [1] [7] [8]. Our patient had no hemostasis abnormality and the dosage of $\mathrm{C}$ and $\mathrm{S}$ proteins was in normal range. This suggests that hemodynamic changes induced by dural puncture may independently have a decisive role in the development of thrombosis. This hypothesis should be considered regardless of indication when spinal anesthesia is performed. The headache of venous thrombosis is usually preceded by post spinal puncture headache (PSPH) [5] [9] as described in our case. PSPH occurs in case of persistent CSF leaks into the epidural space and most often manifest as postural headache [2] [6] [10]. Evolution is usually benign and complications rare [2] [3] [11]. When cerebral venous thrombosis occurs, headaches become permanent. They're no longer relieved by lying down, and standard analgesics or morphin are no longer effective [6] [10]. The change in characteristics of PSPH was observed in our patient. They have become permanent motivating the reconsideration of the diagnosis of PSPH. Clinical signs are rarely typical when it occurs after a spinal anesthesia [7] [10] [11]. Headaches can be isolated as described in our case and lead to a delay in diagnosis. Then it becomes urgent for clinicians to diagnose and treat CVT because of potential serious complications, in the form of cerebral hematomas [1] [4] [8]. Rare similar observations have been reported in the literature, in- 
cluding headache complicated by seizures of epilepsy, motor deficit [1] [7] and disorders of consciousness [11] [12]. These symptoms can be isolated or immediately associated and warrants imaging that found venous thrombosis [7] [10]. The MRI had confirmed the CVT in our practice. Brain magnetic resonance venography (MRV) should be considered the baseline test for accurate diagnosis [6] [13]. It highlights the venous infarction and its seat. MRI in his venous time had helped to appreciate the impact by revealing the lack of flow in the venous sinus as described in the literature [7] [8] [9]. The care then becomes urgent and without delay. Anticoagulation has been shown to be effective and remains the reference treatment [8] [9] [12]. Thus, the evolution was quickly favorable in our patient from the beginning of the administration of the curative anticoagulation to enoxaparin and then to Warfarin. A favorable development without sequelae is also described in published journals [3] [6] [9]. The long-term prognosis of patients with CTV is generally good when diagnosis and early optimal treatment [10] [13]. It combined with better complete functional recovery. However the mortality rate varies from $5 \%$ to $10 \%$ [4] [5] in late forms. A minority of patients with malignant CVT may also benefit from endovascular treatment or decompressive surgery. However, most patients are unable to return to their previous state. A cerebral hernia is the most common cause of death in CVT [12]. Although curative treatment has been shown to be effective, prevention is still of interest. It is important to prevent post spinal headache. Some authors have pointed a direct correlation between needle size and risk of PSPH and suggest that the incidence of PSPH is inversely related to operator experience. Most experts agree that $25-27 \mathrm{G}$ needles probably represent the optimum needle size for spinal anesthesia [10]. Needles with a lower gauge should no longer be used except particular indication. When PSPH occurs, their care must be adequate [7] [11] [12]. The epidural blood patch would be the most effective treatment method, with a high success rate [2] [7] [11] [12]. This treatment has not been used in the management of our patient. The change in the clinical traits of headache as described for our patient or the appearance of neurological signs, must attract attention [3] [9] [10]. If there is any doubt, brain imaging (CT angiography) or magnetic resonance venography (MRV) is necessary so as not to sideline cerebral venous thrombosis. These precautions should be observed in young adult patients and in women during pregnancy due to the increased risk of PSPH and CVT [2] [6].

\section{Conclusion}

Cerebral vein thrombosis is a rare complication of spinal anesthesia and potentially severe if diagnosed lately. It is important that clinicians be alert to any atypical headache or the onset of neurological disorders. Urgent brain imaging should be performed at the slightest doubt, so as not to misunderstand a cerebral vein thrombosis. Good control of spinal or epidural blocks would reduce the inadvertent perforation of the dura-mother that would lead to CVT complicating 
post spinal puncture headache.

\section{Informed Consent}

Written informed consent for publication of clinical details and clinical images was obtained from the patient on Institutional format.

\section{Conflicts of Interest}

The authors declare no conflicts of interest regarding the publication of this paper.

\section{References}

[1] Kate, M.P., Thomas, B. and Sylaja, P.N. (2014) Cerebral Venous Thrombosis in Post-Lumbar Puncture Intracranial Hypotension: Case Report and Review of Literature. F1000Research, 3, 41. https://doi.org/10.12688/f1000research.3-41.v1

[2] Kwak, K.-H. (2017) Postdural Puncture Headache. Korean Journal of Anesthesiology, 70, 136-143. https://doi.org/10.4097/kjae.2017.70.2.136

[3] Parashar, V.K. and Gupta, P. (2018) Cerebral Venous Thrombosis Following Spinal Anesthesia. Journal of Anaesthesiology Clinical Pharmacology, 34, 399-400.

[4] Župan, Z., Tokmadžić, V.S., Matanić-Manestar, M., Šustic, A., Antončić, I., Dunatov, S., et al. (2012) Simultaneous Appearance of Cerebral Venous Thrombosis and Subdural Hematomas as Rare Cause of Headache in Puerperium Following Epidural Analgesia: A Case Report. Croatian Medical Journal, 53, 379-385. https://doi.org/10.3325/cmj.2012.53.379

[5] Reiner, P., Crassard, I. and Lukaszewicz, A.C. (2013) Cerebral Venous Thrombosis. Reanimation, 22, 624-633. https://doi.org/10.1007/s13546-013-0726-3

[6] Mehta, A., Danesh, J. and Kuruvilla, D. (2019) Cerebral Venous Thrombosis Headache. Current Pain and Headache Reports, 23, 7.

https://doi.org/10.1007/s11916-019-0786-9

[7] Barra Bisinotto, F.M., Dezena, R.A., Vilela Abud, T. and Bisinotto Martins, M. (2017) Cerebral Venous Thrombosis after Spinal Anesthesia: Case Report. Brazilian Journal of Anesthesiology, 67, 305-310. https://doi.org/10.1016/j.bjan.2014.09.005

[8] Miglis, M.G. and Levine, D.N. (2010) Intracranial Venous Thrombosis after Placement of a Lumbar Drain. Neurocrit Care, 12, 83-87.

https://doi.org/10.1007/s12028-009-9278-9

[9] Yildiz, O.K., Balaban, H., Cil, G., Oztoprak, I., Bolayir, E. and Topaktas, S. (2010) Isolated Cortical Vein Thrombosis after Epidural Anesthesia: Report of Three Cases. International Journal of Neuroscience, 120, 447-450. https://doi.org/10.3109/00207451003778751

[10] Jabbari, A., Alijanpour, E., Mir, M., Hashem, N.B., Rabiea, S.M. and Rupani, M.A. (2013) Post Spinal Puncture Headache, an Old Problem and New Concepts: Review of Articles about Predisposing Factors. Caspian Journal of Internal Medicine, 4, 595-602.

[11] Roos, C., Concescu, D., Appa Plaza, P., Rossignol, M., Valade, D. and Ducros, A. (2014) Post-Dural (Post-Lumbar) Puncture Syndrome. Review and Retrospective Study at an Emergency Headache Center. Revue Neurologique, 170, 407-415. https://doi.org/10.1016/j.neurol.2014.02.004

[12] Luo, Y., Tian, X. and Wang, X. (2018) Diagnosis and Treatment of Cerebral Venous 
Thrombosis: A Review. Frontiers in Aging Neuroscience, 10, 2. https://doi.org/10.3389/fnagi.2018.00002

[13] Sinha, A., Petkov, S. and Meldrum, D. (2010) Unrecognised Dural Puncture Resulting in Subdural Hygroma and Cortical Vein Thrombosis. Anaesthesia, 65, 70-73.

https://doi.org/10.1111/j.1365-2044.2009.06108.x 